\title{
The fate and behaviour of steroid hormones in wastewater sludge anaerobic digestion at mesophilic and thermophilic temperatures
}

\author{
Stephen Theophilus* \& Augustine O. Ifelebuegu
}

\begin{abstract}
The disposal of biosolids to agricultural land is a major route for recycling municipal wastewater biosolids. However, there are concerns over the long-term build-up of endocrine disrupting chemicals (EDCs), a major constituent of biosolids in agricultural soils and their potential environmental effects. Hence, there is need to investigate the fate and behavior of EDCs in wastewater and sludge treatment processes. This study investigated the fate and behaviour of estrone (E1), 17ß-estradiol (E2) and 17a-ethynylestradiol (EE2) during anaerobic digestion of surplus activated sludge in a batch reactor at mesophilic and thermophilic temperatures. The results showed removal rates of $35 \%, 61 \%$ and $52 \%$ at mesophilic temperatures $\left(35^{\circ} \mathrm{C}\right)$ and $24 \%, 63 \%$ and $79 \%$ at thermophilic temperatures $\left(5^{\circ} \mathrm{C}\right)$ for E1, E2 and EE2 respectively. It was observed that $\mathrm{E} 1 \mathrm{had}$ a lower removal due to biotransformation of E2. Anaerobic digestion contributes to the overall reduction of EDCs in municipal biosolids, but EDCs remained persistent even under thermophilic digestion indicating the need for other treatments in order to achieve total removal.
\end{abstract}

Keywords- EDCs, Anaerobic Digestion, Mesophilic, Thermophilic

\section{Introduction}

Endocrine disrupting chemicals (EDCs) are natural or synthetic compounds that can inhibit the normal functioning of an organism's endocrine system [1-2]. The occurrence of EDCs in effluents from wastewater treatment facilities has led to wide spread concerns [4-5]. The world's population no doubt is on the increase and as such, in major cities, new sewage treatment works are built to cater for this increase and so is the sludge from these treatment plants. The steroid estrogens particularly estrone (E1), 17 $\beta$-estradiol (E2) and $17 \beta$-ethinylestradiol (EE2) have been detected in sewage effluents and sludge across the globe [5-7]. There is, therefore, a rising concern worldwide amongs environmental authorities, local authorities, researchers over the management of sludge, and this has led to enactment of more stringent environmental quality standards, [6]. The major reason for this concern is because many EDCs are resistant to biodegradation and persist in the environment because of their structural stability [5]. Hence, EDCs could spread through sludge disposal because of their resistant to biodegradation during treatment. More perturbing is the potential long-term build-up of EDCs on agricultural land and possible groundwater contamination through leaching when sludge is used as a source of organic nutrient for certain agricultural crops. Hence, there is need to develope technologies and processes to better treat the wastewater sludge and, therefore, reduce EDCs contamination.

*Stephen C Theophilus

School of Energy, Construction and Environment

Coventry University, Priory Street Coventry, Cv1 5FB

United Kingdom
Some modern technologies depend on either physical, chemical or biological or a combination of these to achieve better wastewater targets. Anaerobic digestion is one of the treatment widely used for sewage sludge and research on the fate of EDCs in sludge treatment is limited [8]. In a previous study Ifelebuegu [5] reported the persistence of EDCs following anaerobic treatment of sludge in a full scale treatment plant. Carballa et al. [7] reported the degradation of EE2 by up to $60 \%$ and conversion of E1 to E2 in a laboratory scale anaerobic digester at mesophilic temperatures. In another study, Paterakis et al.[8] reported $>50 \%$ removal of steroid hormones in the digestion of primary and mixed sludge in a laboratory scale plant.

This study seeks to determine the fate of estrogens during anaerobic digestion of surplus activated sludge under mesophilic and thermophilic temperatures. Estrogens E1, E2 and EE2 (Table 1) were chosen for this study because they represent both natural and synthetic estrogens.

Table 1. Structures and Properties of E1, E2 and EE2

\begin{tabular}{|c|c|c|c|}
\hline Chemical & Structure & $\begin{array}{c}\text { Molecular } \\
\text { Weight }\end{array}$ & LogK $_{\text {ow }}$ \\
\hline Estrone(E1) & 270 & 3.13 \\
\hline $\begin{array}{c}17 \beta \text {-estradiol } \\
\text { (E2) }\end{array}$ & 272 & 3.94 \\
\hline $\begin{array}{c}17 \alpha \text {-ethinyl } \\
\text { estradiol } \\
\text { (EE2) }\end{array}$ & 296 & 4.15 \\
\hline
\end{tabular}

\section{Materials and Methods}

\section{A. Materials}

Analytes of interest E1, E2 and EE2 were purchased from Sigma-Aldrich, (Gillingham, UK). All reagents used were from Fischer Scientific (UK). The stock solutions of the EDCs were prepared by dissolving the required amounts in HPLC grade water. Sludge samples were collected from a UK sewage treatment plant and the stabilised sludge was spiked with the fixed concentration of the EDCs. The plant was operated at a sludge age of 12 days. The anaerobic digestion of the stabilized surplus activated sludge was done in a specially constructed laboratory anaerobic batch digesters illustrated in Figure 1. The digesters were kept in a water bath at mesophilic $\left(35 \pm 2{ }^{\circ} \mathrm{C}\right)$ and thermophilic $(55 \pm$ $2{ }^{\circ} \mathrm{C}$ ) temperatures. 


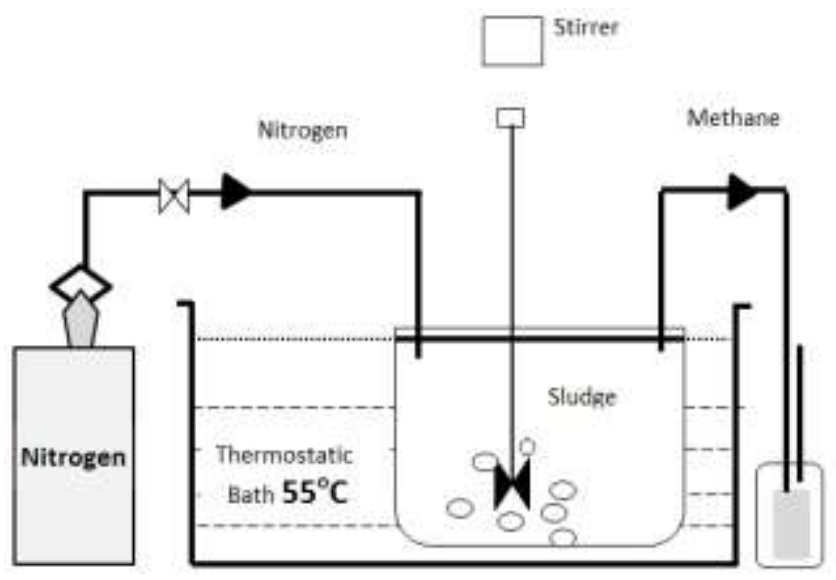

Figure 1-Diagramatic representation of digester set-up

\section{B. Sample Treatment and Analysis}

Details of the methods used to extract sludge samples have been previously described elsewhere [9-10]. The estrogens were analysed using a Hewlett Packard Series 1050 HPLC system. UV detection wavelength was set at $254 \mathrm{~nm}$. The column temperature was set at $25^{\circ} \mathrm{C}$ and flow rate at $1.2 \mathrm{ml} / \mathrm{min}$. The injection was carried out by the use of an automatic syringe pump at $200 \mu$ for 3 minutes. Mobile phase (80:20/methanol: water) was run in an isocratic mode as has been previously described by Ifelebuegu et al. [10].

\section{Results and Discussions}

The degradation of the steroid hormones at mesophilic temperatures are shown in Figure 2. E2 was observed to degrade faster within the first 48 hours and slowly after that. This behaviour was also previously observed [5]. Similar results were also observed at thermophilic temperatures (not shown in this report). There was an initial rise in the concentration of E1 at both mesophilic and thermophilic temperatures in first few days of digestion before a gradual decline. This can be attributed to the usual biotransformation of E2 to E1 during microbial degradation. This has been reported previosuly $[8,10]$.

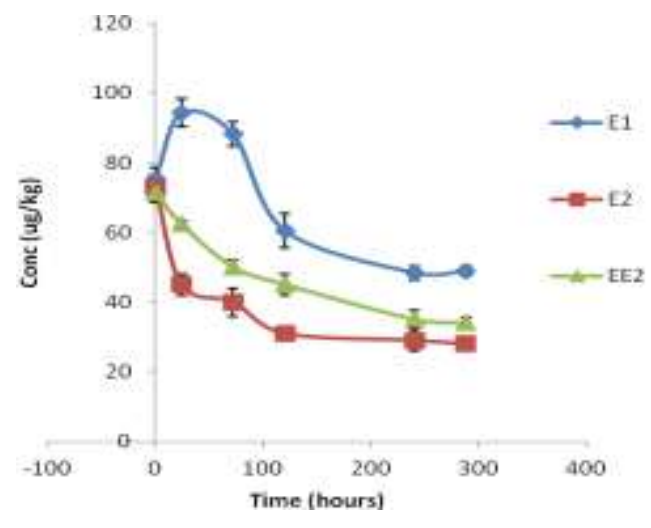

Figure 2. Degradation of the E1,E2 and EE2 at Mesophilic temperature $\left(35 \pm 2{ }^{\circ} \mathrm{C}\right)$.
The effective removal of E1, E2 and EE2 were 34\%, $61 \%$ and $55 \%$ at mesophilic temperatures and 24\%, 63\% and $79 \%$ at thermophilic temperatures respectively. The slightly higher removal at thermophilic temperatures for E2 and EE2 can be attributed to temperature differences. While the lower removal rate of E1 is attributed to the biotransformation of E2 to E1 during the degradation process.

In both mesophilic and the thermophilic conditions, the compound persisted in the final treated biosolids. This result is consistent with the result reported by Ying et al. [11] in the investigation of the fate of estrogens and xenoestrogens in four sewage treatment plants with different technologies, where the removal of estrogens was lower, with rates ranging between 47 and $68 \%$ for E2, while EE2 was more persistent during treatment. Paterakis et al. [8] also reported $>50 \%$ removal of natural steroid hormones during the anaerobic digestion of mixed primary and secondary sludge. While anaerobic digestion at both mesophilic and thermophilic temperatures play a significant role in reducing the EDCs load in treated biosolids; further treatment would be required to eliminate the compounds from municipal sludge.

\section{Conclusion}

This study evaluated the fate of steroid hormones during anaerobic digestion of surplus activated sludge at mesophilic and thermophilic temperatures. The results demonstrated that while both processes significantly reduced the load of the EDCs in digested sludge, they persisted in the treated sludge indicating the need for other treatment process for total removal. Furthermore, effective removal was lower for E1 compared to E2 and EE2 due to the biotransformation of E2 to E1.

\section{Acknowledgement}

The authors wish to express their gratitude to the staff at Coventry University Environmental Laboratory for their support during the laboratory sessions.

\section{References}

[1] Andersen, H., Siegrist, H., Halling-Sorensen, B., Ternes, T. A., 2003. Fate of Estrogens in a Municipal Sewage Treatment Plant, Environmental Science And Technology -Washington DC- VOL 37; Part 18, pp 4021-4026

[2] Dickerson, S.M. and Gore, A.C., 2007. Estrogenic environmental endocrine-disrupting chemical effects on reproductive neuroendocrine function and dysfunction across the life cycle. Reviews in Endocrine and Metabolic Disorders, 8(2), pp.143-159.

[3] Bacaloni, A., Cavaliere, C., Faberi, A., Foglia, P., Samperi, R. and Laganà, A., 2005. Determination of isoflavones and coumestrol in river water and domestic wastewater sewage treatment plants. Analytica chimica acta, 531(2), pp.229-237.

[4] Campbell, C.G., Borglin, S.E., Green, F.B., Grayson, A., Wozei, E. and Stringfellow, W.T., 2006. Biologically directed environmental monitoring, fate, and transport of estrogenic endocrine disrupting compounds in water: a review. Chemosphere, 65(8), pp.1265-1280.

[5] Ifelebuegu, A.O., 2011. The fate and behavior of selected endocrine disrupting chemicals in full scale wastewater and sludge treatment unit processes. International Journal of Environmental Science \& Technology, 8(2), pp.245-254. 
Proc. of the Fourth Intl. Conf. Advances in Bio-Informatics, Bio-Technology and Environmental Engineering- ABBE 2016

Copyright (C) Institute of Research Engineers and Doctors, USA .All rights reserved.

ISBN: 978-1-63248-091-0 doi: 10.15224/ 978-1-63248-091-0-61

[6] Hall, J. Ecological and economical balance for sludge management option, Proceedings of the Workshop on Problems Around Sludge, Stresa (Italy), 18-19 November 1999. Available at: http://ec.europa.eu/environment/waste/sludge/problems

[7] Carballa, M., Omil, F., Ternes, T. and Lema, J.M., 2007. Fate of pharmaceutical and personal care products (PPCPs) during anaerobic digestion of sewage sludge. Water Research, 41(10), pp.2139-2150.

[8] Paterakis, N., Chiu, T.Y., Koh, Y.K.K., Lester, J.N., McAdam, E.J., Scrimshaw, M.D., Soares, A. and Cartmell, E., 2012. The effectiveness of anaerobic digestion in removing estrogens and nonylphenol ethoxylates. Journal of hazardous materials, 199, pp.8895.

[9] Patrolecco, L., Capri, S., De Angelis, S., Polesello, S. and Valsecchi, S., 2004. Determination of endocrine disrupting chemicals in environmental solid matrices by extraction with a non-ionic surfactant (Tween 80). Journal of Chromatography a, 1022(1), pp.1-7.

[10] Ifelebuegu, A.O., Theophilus, S.C. and Bateman, M.J., 2010. Mechanistic evaluation of the sorption properties of endocrine disrupting chemicals in sewage sludge biomass. International Journal of Environmental Science \& Technology, 7(4), pp.617-622.
[11] Ying, G.G., Toze, S., Hanna, J., Yu, X.Y., Dillon, P.J. and Kookana, R.S., 2008. Decay of endocrine-disrupting chemicals in aerobic and anoxic groundwater. Water Research, 42(4), pp.1133-1141. 